of their travel to work (commuting) may be important predictors of disease in their children. ${ }^{12}$ To explore this hypothesis, results are presented from a case-control study of leukaemia in children aged 0-4 years, which was conducted in the vicinity of the nuclear establishments at Aldermaston and Burghfield. ${ }^{3}$

Subjects, methods, and results: Details of the subjects and methods have been previously described. ${ }^{3}$ Briefly, the cases comprised 54 children aged $0-4$ years who had leukaemia or non-Hodgkin's lymphoma diagnosed during 1972-89, who were born in west Berkshire or north Hampshire, and were resident there when their cancer was diagnosed. Four controls per case were selected from hospital delivery registers, and each was individually matched to its corresponding case by sex, date of birth (within six months), mother's age (within five years), and area of residence at birth and time of diagnosis. Because the numbers of informative matched sets were small in many of the analyses, $95 \%$ confidence intervals and $\mathrm{p}$ values for relative risks were calculated using conditional exact methods based on the binomial distribution. However, when more than two levels of exposure were analysed, conditional logistic regression was used to ensure that the estimated risks were consistent for different pairs of exposure levels. ${ }^{4}$

The analyses in the accompanying table relate to the $51(94 \%)$ cases whose parents were interviewed, and their corresponding controls. The total number of subjects used in the various analyses differs with the information source employed. In all instances the maximum amount of available data was input for analysis. Findings are shown separately for two points in time, when the child was born and when the child was diagnosed with cancer; and for two disease groupings, all leukaemias and nonHodgkin's lymphomas combined and acute lymphoblastic leukaemia alone. All variables examined and results presented were selected a priori on the basis of previous suggestions. ${ }^{12}$

Comment: No evidence for an association between the development of leukaemia before age 5 years and a family's estimated level of likely social contact were found in the data examined here (table). The parents of children with leukaemia seem neither more, nor less, likely to have had jobs involving high levels of social contact, live in large towns, or commute to work. As well as the analyses shown, other time periods and factors, such as house moves, residence in specific towns, parental job changes, and a detailed examination of jobs likely to involve particularly high levels of personal contact were investigated but no correlations emerged. Information about specific childhood infections, allergies, and immunisations also yielded no notable case-control differences.

Although our findings do not support the proposition that population mixing at the household level is a risk factor for childhood leukaemia, the possibility that a real effect exists cannot be entirely ruled out since the indicators of exposure used are somewhat crude and the confidence intervals are wide. At the community level, a recent ecological study conducted in France has also failed to find evidence of an increased risk of leukaemia in young people living in areas which sustained rapid population growth between 1968 and $1990 .^{6}$

The suggestion that childhood leukaemia has an infectious aetiology is attractive, and there are many features of the disease which accord with this possibility. More analyses of the type presented here and more information about specific infections are clearly required.

We thank Noreen Maconochie for statistical advice.

1 Kinlen LJ, Hudson CM, Stiller CA. Contacts between adult as evidence for an infective origin of childhood leukaemia: an explanation for the excess near nuclear establishments in West Berkshire? Br f Cancer 1991;64:549-54.

2 Kinlen LJ, Stiller C. Population mixing and excess of child hood leukaemia. BMf 1993;306:930

3 Roman E, Watson A, Beral V, et al. Case-control study of eukaemia and non-Hodgkin's lymphoma among children aged 0-4 years living in west Berkshire and north Hampshire health districts. BMF 1993;306:615-21.

4 Breslow NE, Day NE. Statistical methods in cancer research. Vol 1. The analysis of case-control studies. Lyon: International Agency for research on Cancer, 1980: IARC scientific publications no 82

5 Office of Population Censuses and Surveys. Classification of occupations and coding index. London: HMSO, 1980.

6 . com population increase. Br $\mathcal{F}$ Cancer 1994;69:110-13.

\title{
Spread of influenza: a study of risk factors in homes for the elderly in Wales
}

A Mukerjee

Communicable Disease Control Unit, Mid Glamorgan Health Authority, Abton House, Wedal Road, Cardiff CF4 3QX A Mukerjee

Correspondence to: Dr A Mukerjee. Accepted for publication May 1994
In the winter of 1991-92 there was an outbreak of influenza in the homes for the elderly in Mid Glamorgan. A survey was later carried out to ascertain the risk factors for the spread of infection and their implications on the current policy of influenza immunisation.

Subjects and method: Homes were requested to send the name, age, and influenza vac- cination status of all residents and staff (whole or part time) with the date of onset of influenza defined as "upper respiratory tract symptoms, fever, chills, myalgia, and cough" ${ }^{\text {" between }}$ weeks $91 / 50$ and $92 / 8$. The homes were also asked to provide details of possible risk factors ${ }^{2}$ such as the mean age of the residents, physical characteristics, available facilities, and infection control policy. Paired sera collected 
Comparison of the attack rates between the immunised and unimmunised residents staff in the group I and II homes

\begin{tabular}{|c|c|c|c|c|c|c|c|c|c|c|c|c|}
\hline & \multicolumn{5}{|c|}{ Immunised } & \multicolumn{5}{|c|}{ Unimmunised } & \multirow[t]{2}{*}{$x^{2}$} & \multirow[t]{2}{*}{$p$ value } \\
\hline & No & $\%$ & Ill & Well & $A R \%$ & No & $\%$ & Ill & Well & $A R \%$ & & \\
\hline \multicolumn{13}{|l|}{ Group I homes } \\
\hline Residents & 49 & 47 & 8 & 41 & 16 & 55 & 53 & 14 & 41 & 25 & $1 \cdot 28$ & NS \\
\hline $\begin{array}{l}\text { Staff } \\
\text { Group II homes }\end{array}$ & 3 & 3 & 0 & 3 & 0 & 88 & 97 & 11 & 77 & 12 & $0 \cdot 42$ & NS \\
\hline Residents & 201 & 55 & 54 & 147 & 27 & 161 & 45 & 107 & 54 & 66 & $56 \cdot 59$ & 0.00000001 \\
\hline Staff & 24 & 6 & 2 & 22 & 8 & 357 & 94 & 118 & 239 & 33 & $6 \cdot 35$ & 0.01 \\
\hline
\end{tabular}

from seven affected residents and two staff with the case definition of influenza in two homes at the peak of the outbreak were reported as "consistent with recent infection of influenza A". The Epi info computer package was used for data entry and analysis.

Results: One hundred and eighty three of 466 residents and 129 out of 472 staff were ill in 14 of 17 participating homes. Eighty eight per cent of residents and $91 \%$ of staff who were ill belonged to 11 of the 14 homes $(p<0.0000001)$. Immunisation uptake in the three less affected homes (group I) was not higher than that in the 11 worse affected (group II) homes (table 1). However, there was a significant difference in attack rates between the immunised and unimmunised residents and staff in group II but not in group I homes.

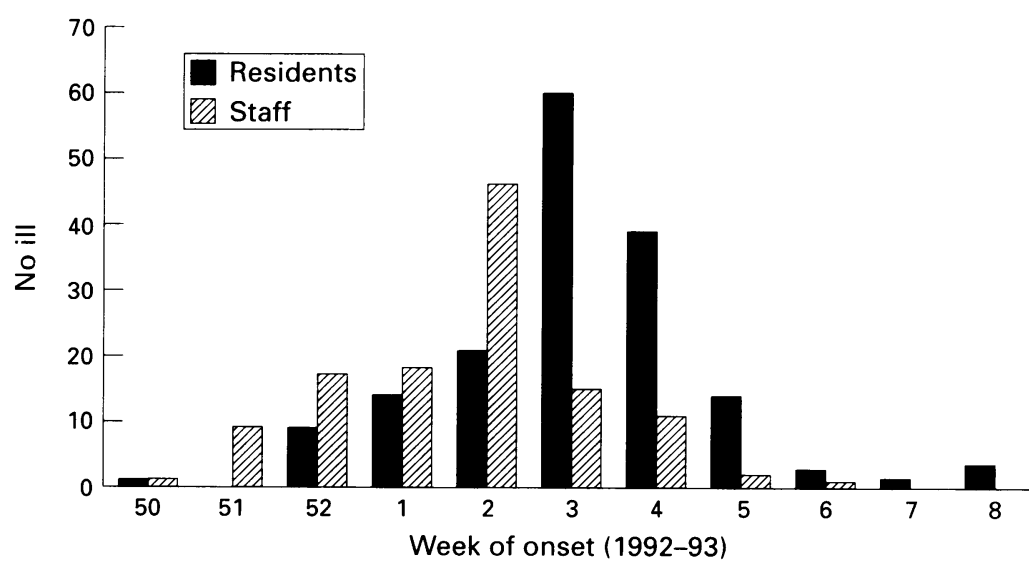

Bar diagram showing, by week of onset, the residents and staff who were ill
There were no differences in the risk factors (stated above) between the two groups of homes except that most (71\%) staff in group II homes were part timers who also worked in other homes or hospitals but none in group I had other care work. When the weekly number of illnesses among the staff and residents were plotted on a bar chart (figure) it was seen that most staff were ill about a week before the residents and could have been responsible for the spread of the infection among the residents.

Discussion: This retrospective survey suggests that the unimmunised staff in the group II homes were responsible for the transmission of infection to the residents. Nearly three quarters of the staff were part timers working elsewhere compared with none in the group I homes where there was hardly any difference in the attack rates between the immunised and the unimmunised population. The present policy ${ }^{3}$ of immunising the residents only is not enough. Care staff should also be immunised, particularly if they are part timers.

I am grateful to all participating Nursing Homes for their cooperation. My sincere thanks to Ms V Caddick for her help in carrying out the survey.

1 Public Health Laboratory Service, Communicable Disease Surveillance Centre, Cardiff. GP surveillance of infections in Wales: case definition of influenza. PHLS, Communicable Disease Surveillance Centre (Welsh Unit), Cardiff. Copy Disease Survellance Centre (Welsh Unit), Cardiff. Copy available on request

Patriarca PA, Weber JA, Parker RA, Orenstein WA, Hall WN, Kendal AP, Schonberger LB. Risk factors for outbreaks of influenza in nursing homes. Am $\mathcal{F}$ Epidemiol 1986;124: $114-19$

3 Joint Committee on Vaccination and Immunisation. Department of Health, Immunisation against infectious disease. London: HMSO, 1992. 